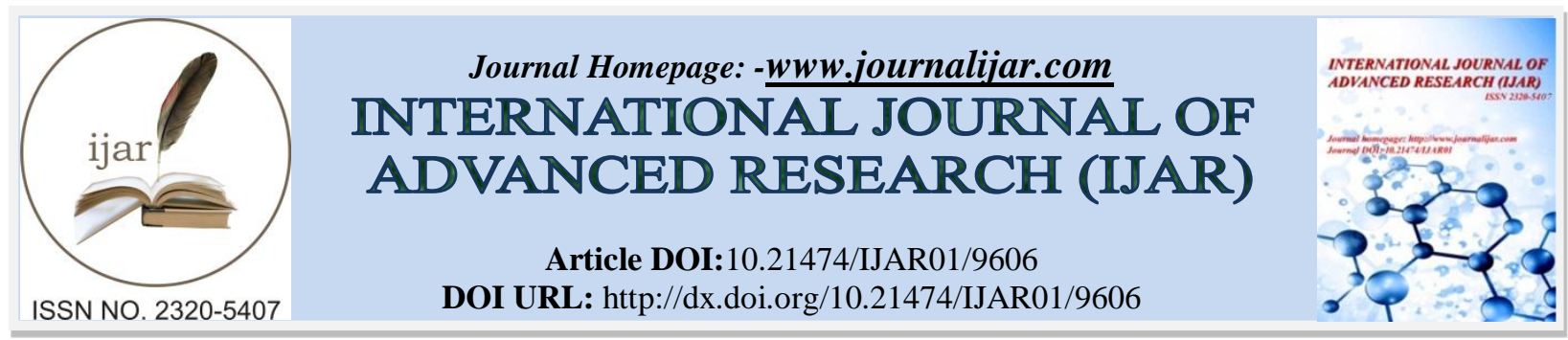

RESEARCH ARTICLE

\title{
ASSESSMENT OF KNOWLEDGE, ATTITUDE AND PRACTICE OF BREAST SELF-EXAMINATION AMONG FEMALE STUDENTS IN WOLAITA SODO UNIVERSITY, ETHIOPIA.
}

TilahunSaol Tura and Masresha Assefa Demissie.

Department of Neonatology and Pediatric Nursing, College of Health Sciences and Medicine,WolaitaSodo University, Wolaita Sodo, Ethiopia.

\section{Manuscript Info}

Manuscript History

Received: 20 June 2019

Final Accepted: 22 July 2019

Published: August 2019

Keywords

Breast, Cancer, BSE.

\section{Abstract}

Introduction: Breast cancer is the most prevalent cancer among women globally and the second commonest cancer overall. In Ethiopia it is also an emerging public health problem and top leading causes of cancer mortality and morbidity among women of reproductive age group. The objectives of research is to assess the knowledge, attitude and practice of breast self-examination among women aged 20-49 years in Wolaita Sodo SNNPR, Ethiopia, 2019.

Method: An institution based cross- sectional study was conducted with a sample of 218 women aged 18-49 years in Wolaita Sodo University. One college wasrandomly selected from three each campus and systematic random sampling technique was used to select female students in the selected campus.A-structured questionnaire is used for assessing female student knowledge, attitude and practice of breast selfexamination by using an open ended and close ended questionnaire. Data qualities was controlled by designating proper data collection tools.

Result: A total of 218 respondents participated in the study, of these, only $83.4 \%$ of them had good knowledge and $95.5 \%$ had positive attitude towards BSE.(83.4\%) of the respondents had done breast selfexaminations, from these only $37.3 \%$ of them practiced monthly.

Conclusion: The finding of the research showing that female students have good attitude but they have poor knowledge and practices toward BSE.

Copy Right, IJAR, 2019,. All rights reserved.

\section{Introduction:-}

Cancer is a major public health trouble in many parts of the world. Breast cancer is one type of cancer which is malignant growth that starts in the cells of the breast. It occurs mostly in women, but men can also be affected (1). An expected 231,840 new cases and 40,290 deaths of breast cancer are expected to occur among women in the US during 2015 (2 (3). In 2013, an estimated 232,340 new cases and 39,620 death of breast cancer is expected to happen in woman.

According to Global Burden of Cancer (GLOBOCAN) 2012, an estimated 14.1 million new cancer cases and 8.2 million cancer-related deaths occurred in 2012, compared with new cancer cases and cancer associated deaths in

Corresponding Author:-TilahunSaol Tura.

Address:-Department of Neonatology and Pediatric Nursing, College of Health Sciences and 
2008 which is 12.7 million and 7.6 million, respectively. Among the most commonly diagnosed cancers global breast cancer accounts $10.9 \%$ and $11.9 \%$ of all cancer cases next to lung cancer in 2008 and 2012 respectively $(4,5)$.In 2011, there were almost 8 million cancer-related deaths. All cancers, taken collectively, are now a leading cause of death worldwide, responsible for $14 \%$ of the total of 55 million deaths from all causes (6). It was reported that it is the most commonly diagnosed cancer and the second principal cause of cancer death among women in 2008 in Africa (92,600 cases, 50,000 deaths). It is also estimated the occurrence of breast cancer in women aged 15 and over in sub-Saharan Africa was 23.5 per 100,000 women in 2008[7, 8]. Breast cancer is the second most often occurring cancer next to cervical tumor among women in Ethiopia. It is estimated that about 10,000 Ethiopian women have breast cancer [9].Data from the Addis Ababa population based cancer registry showed that breast and cervical cancers were the leading cause of cancer comprising $22.6 \%$ and $10.8 \%$ respectively of all cases of cancers in Addis Ababa [10]. As evidences show, reduced awareness of breast cancer symptoms, prevention, risk factors and treatment options have usually been associated with patient impediment in seeking help [11]. The causes of breast cancer are not completely notable. However, researchers have recognized a number of risk factors that increase one's chances of getting breast cancer. These consider; family history of breast cancer, personal history of breast cancer, early menarche, ( $<12$ years), late menopause ( $>55$ years), aging, excessive alcohol use, late age at first fullterm pregnancy ( $>30$ years), never breast feeding a child, high fat diet, tobacco smoking, post-menopausal obesity, new and long term use of hormone replacement therapy, high-dose radiation to chest and lack of physical exercises $[12,13]$.Breast self-examination (BSE) is a easy, very low cost, non-invasive screening method used to find early breast cancer which involves the woman herself looking at and feeling for any change in their breast as early as possible, that issue a better survival rate. Breast self-examination should be done for entirely women above the age of 20 years [14]. Breast cancer screening is a means of distinguishing the occurrence of breast cancers at early stages (before it advancement to the progressive stages). Three important tests are used to screen the breast Cancer. These are breast self-examination (BSE), clinical breast examination (CBE) and mammography [15].Breast selfexamination is done by a woman herself where she assess her own breasts for lumps, alteration in size or shape of the breast or any other changes in the breast or underarm. It doesn't substitute regular screening mammograms or clinical breast examination. However, regular carrying out of BSE does not mean that the breast cancer is needs selfdetected. Although, the American Cancer Society recommended in 2003 that women first in their 20s should be told about the gain and limitations of BSE, this procedure is not reasoned the best method for early detection of breast cancer but is the best alternative for interval screening among women of all ages [16, 17].

Breast cancer is also the most common cause of cancer death among women (522,000 deaths in 2012) and the most oftentimes diagnosed cancer among women in 140 of 184 countries worldwide. It is also the leading cause of cancer death in less developed countries of the world. The incidence of breast cancer is higher in matured countries but the mortality is higher in less developed countries due to lack of early find and management service as well as limited awareness of early signs and symptoms of cancer among the public and health care give $[4,18]$.

Unlike early sensing in western world, women in Ethiopia usually present late screening for breast cancer and are expected to have a very limited life span. The Oncologic service in Ethiopia is limited to only one Radiotherapy Center at Black Lion Specialized Hospital [19].

In Ethiopia, It is idea that around 10,000 Ethiopian women have breast cancer with thousands of more cases unreported because the women living in rural areas preferred a treatment from traditional healers. In Ethiopia, Breast cancer become lethal due to late presentation, limited resources, low awareness of breast cancer and its detection, symptoms, prevention and strong traditional beliefs that can delay biomedical care [20].Therefore, many women failure early detection and treatment opportunities due to lack of information, knowledge, and practice of early detection of breast cancer.

In Ethiopia, communicable and chronic diseases have been given a major concern and all the efforts and recourses are involved into them. Government, non-governmental organizations and worldwide partners all focused to these diseases. The detection and management of reproductive organ cancers (ROCs), particularly breast cancer is low. Despite its prevalence ROCs are not treated as a major public health issues at any levels of health care delivery system. Nationally, there is no formed ROC prevention, education, screening or curative care program. Little is known about the scale of the problem, which makes it all the more hard to formulate policies and/or develop practical strategies for dealing with it. It may be one of the reasons for absence of sufficient facilities to fight against breast cancer in this country [20,21]. 
Even though women knew about the different breast cancer screening methods, findings from female Medical Students in Haramaya University, Ethiopia, indicated that the practice of BSE while perceived as being essential is not frequently practiced by the students [22]. Prevention remains the base of the fight against breast cancer. In order to prevent or decrease the mortality, morbidity of breast cancer diagnosis of breast cancer during the early stage of the disease play big role and it helps in reducing the cost of management [23].

The screening methods for early detection of this fatal disease are: mammography, clinical breast investigating and breast self-examination. Although some early find methods, may remain inaccessible to women in developing countries due to limited diagnostic and curative facilities. Mammography cannot be routinely applied in countries with limited health service resources [24], since it is expensive it needs technology and skilled professional. CBE also need professional ability and health facility visit to be conducted [23].BSE is still recommend as a general approach to increasing breast health awareness and allows for early detection of any abnormalities. BSE continues to be recommended by health care practitioners because it is free, simple, need low technology and teaching is possible [25]. BSE also recommended in low resource countries like Ethiopia where resources are inadequate (mammography is not available) for early breast cancer detection [22].

Moreover limited studies are conducted about BSE knowledge and activity among student's calls for exploration of knowledge and practice of BSE among female students.

\section{Method:-}

\section{Study area and period}

Wolaita zone is one of the zones in Southern Nations, Nationalities and Peoples Region (SNNPR). It is bordered on the south by Gamo Gofa, on the west by the Dawro zone which on the northwest by KembataTembaro, on the north by Hadiya, on the northeast by the Oromia Region, on the east by the Bilate River which separates it from Sidama, and on the south east by the Lake Abaya which separates it from Oromia Region. The administrative center of Wolaita Zone is Sodo. Wolaita Sodo University lies at an altitude of 1240 meters above sea level with average temperature of $25^{\circ} \mathrm{c}$. The University has 3 campus (main, Otona, and Tercha campus). It consists faculty of engineering, business and economics, agriculture, medical and health and social science. The data were collected from March 01-15/2019

\section{Study design}

Institutional based cross sectional study was used

\section{Source Population}

All female students in Otona campus, Wolaita Sodo University

\section{Sample Size Determination}

Estimating the sample size of female students to be interviewed from the total female students in the campus is calculated using standard formula:

$\mathbf{N}=\mathbf{Z}^{2}(1-\mathbf{P})$ where by $D^{2}$

$\mathbf{Z}=$ confidence interval of $95 \%(1.96)$

$\mathbf{P}=$ confidence interval of 23\%) [40]. Breast Cancer Awareness and Practice of Breast Self- Examination among Female Students in Wolaita Sodo University Otona Campus, Wolaita Sodo Ethiopia

$$
\begin{aligned}
& \text { 1-P = Proportion of negative Character as } 35.5 \% \\
& \mathbf{D}^{2}=\text { Allowable error to be considered } 5 \% \\
& \mathbf{N i}=\text { total sample size } \\
& \mathbf{N i}=\left(1.96^{2} \times \mathrm{p}(1-\mathrm{P})\right. \\
& (0.05)^{2} \\
& =(1.96)^{2} \mathrm{X}(0.23)(0.77)=272 \\
& (0.05)^{2}
\end{aligned}
$$

Total number of female student in wsu in otona campus is source population 585 which is less than 10,000 by using correction formula the final Sample size was 218.

\section{Sampling Technique}

Simple random sampling method was used to select the study subjects. Wolaita Sodo University has three campuses, from the 3 campuses, Otona campus is selected by simple random sampling (lottery) method. Then the list of female students in the selected campus was taken from the registrar of main campus. Finally the participants were selected 
from all female in the campus by using simple random sampling from all departments of College of Health Sciences and Medicine.

\section{Data Collection and Analysis}

A-structured questionnaire was used for assessing female student knowledge, attitude and practice of breast selfexamination by using an open ended and close ended questionnaire. Data was collected by ourselves. The questionnaire is prepared in English, translated into Amharic and then retranslated back in to English to check for consistency. The questionnaire contained four parts, comprising of socio demographic characteristics, Knowledge, practice and attitude about BSE.The data collectors can speak both Amharic and English languages.

Data qualities were controlled by designating proper data collection tools which was prepared by investigator and data collector under regular supervision and data were cleared and checked in the field. The data was processed and analyzed by scientific calculator. Locally available materials such as pencil, pen, scientific calculators, ruler were used to analyze data since it is descriptive.

\section{Ethical Consideration}

Letter of permission was written from the Wolaita Sodo University submitted to Wolaita Sodo University. The study process has no harm to the study population and confidentiality was kept. The study unit who was not be voluntary to be exclude in the study was not enforce to be included in the study

\section{Result:-}

\section{Socio- demographic characteristics of the respondents}

A total of 218 students responded the questionnaire (response rate 100\%). The mean age of the participants was 23 years and the majority age between 18-22 (51.8\%) respondents were less than 22 years old. Fifthly seven percent of respondents were Orthodox in religion and more than $89 \%$ of them were single $67.8 \%$ and $65.6 \%$ of respondents' fathers and mothers attended higher education, level respectively.

Table 1:-Socio demographic characteristics of the female study participants in Wolaita Sodo University College of Health Science and Medicine, 2019

\begin{tabular}{|c|c|c|}
\hline Variable & Frequency & Percentage $(\%)$ \\
\hline Sex & 218 & $100 \%$ \\
\hline \multicolumn{3}{|l|}{ Age } \\
\hline $18-22$ & 113 & $51.8 \%$ \\
\hline $23-27$ & 101 & $46.3 \%$ \\
\hline$>=28$ & 4 & $1.83 \%$ \\
\hline \multicolumn{3}{|l|}{ Marital status } \\
\hline Single & 195 & $89.4 \%$ \\
\hline Married & 21 & $9.6 \%$ \\
\hline Widowed & 0 & \\
\hline Separated & 2 & $0.9 \%$ \\
\hline Divorced & 0 & 0 \\
\hline \multicolumn{3}{|l|}{ Year of study } \\
\hline $1^{\text {st }}$ Year & 45 & $20.7 \%$ \\
\hline $2^{\text {nd }}$ Year & 35 & $16.1 \%$ \\
\hline $3^{\text {rd }}$ Year & 60 & $27.5 \%$ \\
\hline $4^{\text {th }}$ Year & 40 & $18.3 \%$ \\
\hline $5^{\mathrm{TH}}$ and above & 38 & $17.4 \%$ \\
\hline \multicolumn{3}{|l|}{ Mother's education } \\
\hline Illiterate & 10 & $4.58 \%$ \\
\hline Read and write & 35 & $16 \%$ \\
\hline Elementary school & 30 & $13.76 \%$ \\
\hline Secondary school and above & 143 & $65.59 \%$ \\
\hline \multicolumn{3}{|l|}{ Father's education } \\
\hline Illiterate & 15 & $6.9 \%$ \\
\hline
\end{tabular}




\begin{tabular}{|l|l|l|}
\hline Read and write & 25 & $11,5 \%$ \\
\hline Elementary school & 30 & 13.76 \\
\hline Secondary school and above & 148 & $67.8 \%$ \\
\hline Religious & & \\
\hline Protestant & 70 & $32.1 \%$ \\
\hline Orthodox & 125 & $57.3 \%$ \\
\hline Muslim & 18 & $8.3 \%$ \\
\hline Other & 5 & $2.3 \%$ \\
\hline Place of birth & & \\
\hline Urban & 176 & $80.7 \%$ \\
\hline Rural & 42 & $19.3 \%$ \\
\hline Department & & \\
\hline Nursing & 78 & $35.7 \%$ \\
\hline Public health & 41 & $18.8 \%$ \\
\hline Laboratory & 28 & $12.8 \%$ \\
\hline Midwife & 28 & $12.8 \%$ \\
\hline Anastasia & 6 & $2.75 \%$ \\
\hline Pharmacy & 17 & $7.7 \%$ \\
\hline Medicine & 20 & $9.17 \%$ \\
\hline
\end{tabular}

\section{Knowledge of breast self-examination}

Majority of theme $95 . \%$ of the respondents had good knowledge and the rest 10 (4.6\%) have poor knowledge regarding breast cancer. Almost all of the respondents heard about breast cancer. Mass media was the main primary source of information followed by health workers

Table 2:-Knowledge score and knowledge on information of Breast cancer among the study participants in Wolaita Sodo University College of Health Science and Medicine, 2019

\begin{tabular}{|l|l|}
\hline Variable & Frequency AND PERCENT (\%) \\
\hline Knowledge score & \\
\hline Good & $208(95 \%)$ \\
\hline Poor & $10(4 \%)$ \\
\hline Do you know about breast cancer & \\
\hline Yes & $208(95.4 \%)$ \\
\hline No & $10(4.6 \%)$ \\
\hline Is breast cancer transmittable? & \\
\hline Yes & $20(9.2 \%)$ \\
\hline No & $198(90.8 \%)$ \\
\hline Do you know risk factor. & \\
\hline Gender & $168(77 \%)$ \\
\hline Aging & $53(24.3 \%$ \\
\hline Family history & $102(46.78 \%)$ \\
\hline Smoking & $21(9.63)$ \\
\hline Early menarche & $5(2.2)$ \\
\hline Late menopause & $3(1.37 \%)$ \\
\hline Other & $2(0.9 \%)$ \\
\hline Symptom of breast ca. & \\
\hline Breast pain & $50(22.9 \%)$ \\
\hline Painless and hard mass & $60(27.5 \%)$ \\
\hline Breast discharge other than milk & $5525.2 \%)$ \\
\hline Redness of nipple & $53(24.3 \%)$ \\
\hline Early detection & \\
\hline Yes & $178(81.7 \%)$ \\
\hline No & $40(18.3 \%)$ \\
\hline & \\
\hline & \\
\hline
\end{tabular}




\begin{tabular}{|l|l|}
\hline Know types of breast ca screening & \\
\hline Yes & $195(89.4 \%)$ \\
\hline No & $23(10.6 \%)$ \\
\hline Know kinds of screening method & \\
\hline BSE by themselves. & $63(32.3 \%)$ \\
\hline By health professionals & $60(30.8 \%)$ \\
\hline Mammography & $70(35.8 \%)$ \\
\hline Other & $2(1 . \%)$ \\
\hline Heard about BSE & \\
\hline Yes & $150(68.8 \%)$ \\
\hline No & $68(31 \%)$ \\
\hline Source of information BSE & \\
\hline Health profession & $43(28.7 \%)$ \\
\hline Friends & $34(22.7 \%)$ \\
\hline Mass media & $73(48.7 \%)$ \\
\hline Age BSE began & \\
\hline$<20$ & $63(42 \%)$ \\
\hline$>20$ & $84(56 \%)$ \\
\hline Any time & $3(2 \%)$ \\
\hline BSE performing time & \\
\hline Daily & $17(11.3 \%)$ \\
\hline Weekly & $31(20.6 \%)$ \\
\hline Monthly & $56(37.3 \%)$ \\
\hline Yearly & $46(30.6 \%)$ \\
\hline
\end{tabular}

\section{Attitude of breast self-examination}

Attitude towards breast self-examination Most $(83.5 \%)$ of the participants agree that breast self-examination has benefit and majority $(65.1 \%)$ were early screening of breast self-examination was highly desirable. Majority of the participants (78.4\%) reported that they would disagree wasting time of BSE.

Table 5:-Assessment on attitudeof female students towards BSE in Wolaita Sodo University College of Health Science and Medicine, 2019.

Practice of breast self-examination

\begin{tabular}{|c|c|c|}
\hline Questions & Options & Frequency $(\%)$ \\
\hline \multicolumn{3}{|l|}{ Attitude } \\
\hline \multirow[t]{2}{*}{ Breast cancer is preventable and treatable disease if detected early } & Agree & $125(57.4 \%)$ \\
\hline & Disagree & $93(42.3)$ \\
\hline \multirow{2}{*}{$\begin{array}{l}\text { Screening is necessary for early detection and prevention of breast } \\
\text { cancer. }\end{array}$} & Agree & $140(64.2 \%)$ \\
\hline & Disagree & $75(34.4 \%)$ \\
\hline \multirow{2}{*}{$\begin{array}{l}\text { Early breast screening procedure is effective in detecting breast } \\
\text { cancer. }\end{array}$} & Agree & $160(73.3 \%)$ \\
\hline & Disagree & $58(26.6 \%)$ \\
\hline \multirow[t]{2}{*}{ Early breast detection can improve chance of survivals } & Agree & $100(45.8 \%)$ \\
\hline & Disagree & $118(54.1)$ \\
\hline \multirow[t]{2}{*}{ Screening is cost effective } & Agree & $160(73.4 \%)$ \\
\hline & Disagree & $58(26.6 \%)$ \\
\hline \multirow[t]{2}{*}{ You are interested to do breast self-examination } & Agree & $90(41.2 \%)$ \\
\hline & Disagree & $128(58.7 \%)$ \\
\hline \multirow[t]{2}{*}{ Doing BSE is wasting time } & Agree & $47(21.5 \%)$ \\
\hline & Disagree & $171(78.4 \%)$ \\
\hline
\end{tabular}

Practice breast self-examination Students were asked if they practice early detection measures i.e. BSE as a means of diagnosis of breast cancer; majority of the participants $182(83.4 \%)$ replied they practice BSE. Only 36(16.5\%) participants did not practiced BSE. Of the participants who practiced BSE, 46(25.2\%) practiced BSE monthly, 
$47(25.8 \%)$ were practiced once every three month, 24(13.1\%) and 41(22.5\%) were practiced once in a six months and in a once yearly respectively.

Table 6:-Assessment on BSEpractices of Female studentsin Wolaita Sodo University College of Health Scienceand Medicine, 2019

\begin{tabular}{|c|c|}
\hline Variables & Frequency $(\%)$ \\
\hline \multicolumn{2}{|l|}{ Have you ever performed Breast self-examination? } \\
\hline Yes & $182(83.4 \%)$ \\
\hline No & $36(16.5 \%)$ \\
\hline \multicolumn{2}{|l|}{ How often you practice Breast self-examination? } \\
\hline A. Once in a week & $21(11.5 \%)$ \\
\hline B. Once in a month & $46(25.2 \%)$ \\
\hline C. Once in 3month & $47(25.8 \%)$ \\
\hline D. . Once in 6month & $24(13.1 \%)$ \\
\hline E. Once in a year & $41(22.5 \%)$ \\
\hline F. Other specify & $3(1.6 \%)$ \\
\hline \multicolumn{2}{|l|}{$\begin{array}{l}\text { Why do/did you perform breast } \\
\text { Self- examination? }\end{array}$} \\
\hline A. Fear of breast cancer from family history & $7(3.8 \%)$ \\
\hline B. Recommended by Health professional & $33(18.1 \%)$ \\
\hline C. For early detection and treatment & $71(39.0 \%)$ \\
\hline E. Fear of developing breast cancer & $39(21.4 \%)$ \\
\hline F. Other, specify & $32(17.6 \%)$ \\
\hline \multicolumn{2}{|l|}{ Age that you started practicing breast self- examination? } \\
\hline A. Les s than 20 years of a g e & $78(42.9 \%)$ \\
\hline B. Between 25 and 30 years of age & $104(57.1 \%)$ \\
\hline \multicolumn{2}{|l|}{ When do you perform Breast self-examination } \\
\hline A. 2 to 3 days after session of menstruation & $23(12.6 \%)$ \\
\hline B. When it comes to mind & $71(39 \%)$ \\
\hline C. A regular days of each month & $6(3.3 \%)$ \\
\hline D. few days before menses & $15(8.2 \%)$ \\
\hline E. any time during the month & $67(36.8 \%)$ \\
\hline \multicolumn{2}{|c|}{ If you don't practice breast self-examination, what are your reasons? } \\
\hline A. I don't have a breast problem & $17(47.2 \%)$ \\
\hline B. Would not gain benefit from practicing it & $5(13.8 \%)$ \\
\hline C. It's not comfortable & $2(5.6 \%)$ \\
\hline D. Fear of detecting abnormalities & $12(33.3 \%)$ \\
\hline
\end{tabular}

\section{Discussion:-}

From this study, almost majority of the respondents have heard about cancer, which is higher than the study in Iraq, where about $95 \%$ of the respondents heard about breast cancer [45]. Media was most the source of information about breast cancer for first time. A similar finding was reported in Ethiopia and other different studies like in Iraq 2011, Nigeria, Ghana [44,46,-47]. This indicates that media is playing major role in creating awareness about female cancer in most of the world and there is a need of health professionals' involvement creating awareness through health educations.

This study showed that, majority of the respondents had knowledge of breast cancer but few of them (10\%) have poor knowledge level. A study done in Iraq 2011 and 2012, Saudi Arabia 2013, Pakistan in 2010, in Nigeria 2008, Ghana, Ethiopia [45,46,47-50] reported low knowledge score among majority of the respondents. But in a study done in Nigeria in 2008 a better breast cancer knowledge level was obtained. This is expected considering the fact that they are health science students and must have acquired this knowledge during their education. Previous studies have reported the roles played by formal and non-formal education in health related issues. 
Concerning their knowledge on the frequency BSE, 182 (83.5\%) of the respondents correctly reported that BSE should be done monthly. This finding is significantly lower than by half from a study done in Saudi Arabia in 201, where, $89.2 \%$ of the participants knew that BSE is recommended to be done monthly [48].

Nearly $20.6 \%$ of the respondents reported that BSE should be performed a week after menses. Similar findings of Saudi Arabia less than half (46.8\%) of the respondents aware that should be performed A week after menses BSE [48] and a study in Ghana, 62\% stated some days after menstruation [47]. In this study, about $83 \%$ of the respondents had a positive attitude toward BSE. A study done in Saudi Arabia more than two third of the respondents had positive attitude toward BSE [48] While a study conducted in, Iraq $89.7 \%$ of the female had positive attitude toward learning the correct procedure of BSE with an intention to instruct others on the technique [45] and Nigeria in 2008 showed that from 100 health workers, [92\%] positive attitude [50]. This difference may be due to the level of knowledge between Nigerian health workers and health students in our case and in other way the sample size taken Nigeria was small compared to our study.

In our study the knowledge score was associated with the practice of BSE. In contrast to this studies like, in Iraq in 2012 an Ethiopia in 2014 the knowledge score of the respondents was associated with practice of BSE [44,45]. The reason could be in our setting, the study was conducted among health professional's students, so there might not be such significant difference of knowledge score was not noted about BSE. In addition the educational level of the respondents show association with practice toward BSE. In contradictions in a study done Ghana level of education is factor associated with practice toward BSE [47].

\section{Conclusion:-}

The finding of this research showing that female student have good attitude BSE. Even though they have good attitude toward BSE, their practice and knowledge toward the BSE is very poor. Therefore, qualitative research is recommended to be conducted to identify the factors that affect the practices and knowledge toward BSE of females.

\section{Declaration:}

this article is our original work. It is not directly copied from any other research. All articles used for preparation of the manuscript were cited properly.

\section{Acknowledgement:-}

We would like to acknowledge Wolaita Sodo University, Department of nursing staff for their valuable comments and suggestion in preparation of this manuscript.

\section{Reference:-}

1. American Cancer sociey. Breast Cancer. 2014. Available from: http://www.cancer.org

2. American Cancer sociey. Cancer Facts \& Figures 2015.Vol. Special Se. 2015. Available from: www.cancer.org

3. American cancer Society. breast cancer facts and figures 2013-2014. 2013.

4. World Health Organization. Latest world cancer statistics. In: international agency for research cancer. 2013.

5. Ferlay J, Soerjomataram I I, Dikshit R, Eser S, Mathers C, Rebelo M, et al. Cancer incidence and mortality worldwide: sources, methods and major patterns in GLOBOCAN 2012. Int J Cancer. 2014;136(5):E359-86. Available from: http://www.ncbi.nlm.nih.gov/pubmed/25220842\ nhttp://globocan.iarc.fr/ Pages/factsheets population.aspx

6. World health Organization. International Agency for Research on Cancer . 2012. Available from: http://www.golobocan.iarc.fr

7. A Jemal, F.B. et al. Center and D. M. ParkinCancer burden in Africa and opportunities for prevention. GLOBOCAN 2008, 2012;118(18): p. 4372-4384.

8. Bray F, R.J., Masuyer E, Ferlay J , Global estimates of cancer prevalence for 27 sites in the adult population Int J Cancer, 2008; 132(5):: p. 1133-1145.

9. pharmaceuticals, a., findings from first-ever initiative on sustainable breast cancer treatment in the developing world; 2010. p. <http://www.csrwire.com/>.

10. National Strategic Action Plan(NSAP) For Prevention And Control Of Non-Communicable Disease In Ethiopia :2014-2016

11. CH, Y. Breast health in developing countries , 2008; referenced on september,2014.

12. American Cancer Society, Breast cancer facts and figures, Atlanta. 2007-2008;www.iosrjournals.org 
13. American Cancer Society,Breast cancer facts and figures. Atlanta. . 2009-2010; www.iosrjournals.org

14. Burke, K. M., LeMone, P., and Mohn-Brown EL. Medical-surgical nursing care. 2nd edtion. Prentice Hall: Pearson; 2007.

15. Ali, T.S., Baig, S. ,Evaluation of a cancer awareness campaign: experience with a selected population in Karachi. Asian Pacific Journal of Cancer Prevention, 2006;7: p. 391-395.

16. Mandelnlatt JS, C.K., Bailey S, et al, effects of mammography screening under different screening schedules: model estimates of potential benefits and harms. Annals of internal medicine 2009; 151(10): p. 738747[PubMed].

17. Sung JF, B.D., Coates RJ, Alema-MensahE. ,Knowledhe, beliefs, attitudes, and screening among inner-city African American Women. J Natl Med Assoc. , 1997;89(6): p. 405-11.

18. American cancer Society. Cancer in Africa.Int agency Res cancer . 2008; Available from: http://www.cancer.org

19. Anderson BO, Shyyan R, Eniu A, Smith R a, Yip C-H, Bese NS, et al. Breast cancer in limited-resource countries: an overview of the Breast Health Global Initiative 2005 guidelines. Breast J . 2006;12Suppl 1:S3-15. Available from: http://www.ncbi.nlm.nih.gov/pubmed/16430397

20. Dye TD, Bogale S, Hobden C, Tilahun Y, Deressa T, Reeler A. Experience of Initial Symptoms of Breast Cancer and Triggers for Action in Ethiopia. Intrational J breast cancer. 2011;2012:1-5.

21. Federal Democratic Republic of Ethiopia Minstry of Health. National reproductive health strategy 2006-2015.

22. Ameer K, Abdulie SM, Pal SK. Breast Cancer Awareness and Practice of Breast Self-Examination among Female Medical Students in HaramayaUniversity,Harar , Ethiopia. Int J InterdiscipMultidiscip Stud (IJIMS),. 2014;2(2348 -0343):109-19. 48

23. Montazeri A, Vahdaninia M, Harirchi I, Harirchi AM, Sajadian A, Khaleghi F, et al. Breast cancer in Iran : need for greater women awareness of warning signs and effective screening methods. Asia Pac Fam Med. 2008;7:17. Available from: http://www.apfmj.com/content/7/1/6

24. Pc G, Nielsen M. Screening for breast cancer with mammography ( Review ). cochraneCollab. 2011;(1).

25. Ginsberg GM, Lauer JA, Zelle S, Baeten S, Baltussen R. Cost effectiveness of strategies to combat breast , cervical, and colorectal cancer in sub-Saharan Africa and South East Asia : mathematical modelling study. 2012;614(March):1-18.

26. SemaryaBerheLemlem, WorkineshSinshaw, et.al. Assessment of knowledge of breast cancer and screening methods among nurses in university hospitals in Addis Ababa, Ethiopia.ISRN Oncology 2011; vol. 2013. Available at htt://dx.doi.org/10.1155/2013/470891

27. Maznah Dahlui1*, Daniel EngHwee Gan1, et.al. Predictors of Breast Cancer Screening Uptake: A Pre Intervention Community Survey in Malaysia. Asian Pacific Journal of Cancer Prevention, 2012; Vol 13, 201 DOI:http://dx.doi.org/10.7314/APJCP 13.7.3443

28. Ricci, Susan Scott. Women's health throughout the lifespan: Maternity and pediatric nursing; 2009 Wolters Kluwer Health | Lippincott Williams \& Wilkins, 180-196.

29. International Agency for Research on Cancer. GloboCan 2008 - Cancer Fact Sheet. http://globocan.iarc.fr/factsheet.asp

30. Nasiru A Ibrahim*1 and Olumuyiwa O Odusanya2 ,Knowledge of risk factors, beliefs and practices of female healthcare professionals towards breast cancer in a tertiary institution in Lagos, Nigeri, 2009. available at: (http://www.biomedcentral.com/1471 2407/9/76

31. WHO. World Health Organization Cancer.2010. Available at http://www.who.int/ media centre/factsheets/fs297/en/.

32. Lance arm strong foundation cites Ethiopia breast cancer Initiative as global model for action, First Live STRONG Global Cancer Summit Spotlights Axios Effort to Address Growing Breast Cancer Incidence in Poor Countries; AstraZeneca global pharmaceutical company, available at: astrazeneca.com

33. American cancer society, Breast Cancer Early Detection available at http://www.cancer.org/acs/groups/cid/documents/web content/003165

34. Alsaif A.A Breast self examination among Saudi female nursing students in Saudi Arabia Saudi medical journal 25(11):1574

35. American Cancer Society, Breast Cancer Facts \& Figures. Atlanta; 2005-2006.

36. Smith, R.A., Cokkinides, V. and Eyre, H.J. American Cancer Society Guidelines for the Early Detection of Cancer. CA Cancer J Clin. 2005. 55 (1):31-44.

37. Ahuja, S., and Chakrabarti, The Internet Journal of Public Health N. 2010.1 (1).

38. Addis Ababa cancer registry. 2012. 
39. ÖzgülKarayurt*1, Dilek Özmen2 et.al. Awareness of breast cancer risk factors and practice of breast self examination among high school students in Turkey. Available from: http://www.biomedcentral.com/1471$2458 / 8 / 359$

40. Ethiopian cancer association (ECA) 2007, available at: http://www.yeeca.org/Breast Cancer.htm.

41. McCready T, Littlewood D, Jenkinson J. Breast self-examination and breast awareness: A literature review. J ClinNurs; 2005. 14(5): 570-578.

42. U.M.D. Gwarzo, K. Sabitu and S. H. Idris.2009; Knowledge And Practice Of Breast-Self Examination Among Female Undergraduate Students Of Ahmadu Bello University Zaria, Northwestern Nigeria, Annals of African Medicine Vol. 8, No. 1: 55 - 58.

43. OAbimbolaOluwatosin. Primary health care nurses' knowledge practice and client teaching of early detection measures of breast cancer in Ibadan. BMC Nursing2012

44. Legesse B, GedifT(2014) Knowledge on breast cancer and its prevention among women household heads in Northern Ethiopia. Open Journal of Preventive Medicine 4:32-40.

45. Nada ASA, Jwad KA, Wafa'M Al-At, Raghad AE(2012) Knowledge, attitude \& practice towards breast cancer \& breast self-examination in Kirkuk University, Iraq.

46. Samina K, Warda Q, Saqib M, Afaf S, Sumbal M(2011) Knowledge, Attitude and Preventive Practices of Women for Breast cancer in the Educational Institutions of Lahore, Pakistan. Asian Pacific J Cancer Prev12:2419- 2424.

47. Sarfo LA,Awuah-Peasah D, Acheampong E, Asamoah F(2013) Knowledge, attitude, and practice of self-breast examination among female university students at Presbyterian University College, Ghana. American Journal of Research Communication 1: 395-404.

48. Dalal MN, Sahar HA, Al-HanoufAA,Abrar AO, Eiman MA (2014) Knowledge, attitude and practice of breast self-examination and breast cancer among female medical students in Taif, Saudi Arabia, 4: 69-77.

49. Gebrehiwot H, Hailu T, Gidey G(2014) Knowledge and Attitude towards Breast Cancer among Mekelle University Female Regular Undergraduate Students, Tigray Region, Ethiopia, 2013. Sch J App Med Sci 2:766772.

50. Oluwole OC(2008) Practice of Breast-Self Examination: Awareness, Knowledge and Practice of Breast-Self Examination amongst Female Health Workers in a Nigerian Community 3:100-103. 